\title{
Adherence and health care costs
}

This article was published in the following Dove Press journal:

Risk Management and Healthcare Policy

20 February 2014

Number of times this article has been viewed

\author{
Aurel O luga ${ }^{1,2}$ \\ Maura J McGuire 3,4 \\ 'Johns Hopkins Bloomberg \\ School of Public Health, ${ }^{2}$ Johns \\ Hopkins University, ${ }^{3}$ Johns Hopkins \\ Community Physicians, ${ }^{4}$ Johns \\ Hopkins University School of \\ Medicine, Baltimore, MD, USA
}

\begin{abstract}
Medication nonadherence is an important public health consideration, affecting health outcomes and overall health care costs. This review considers the most recent developments in adherence research with a focus on the impact of medication adherence on health care costs in the US health system. We describe the magnitude of the nonadherence problem and related costs, with an extensive discussion of the mechanisms underlying the impact of nonadherence on costs. Specifically, we summarize the impact of nonadherence on health care costs in several chronic diseases, such as diabetes and asthma. A brief analysis of existing research study designs, along with suggestions for future research focus, is provided. Finally, given the ongoing changes in the US health care system, we also address some of the most relevant and current trends in health care, including pharmacist-led medication therapy management and electronic (e)-prescribing.
\end{abstract}

Keywords: patient, medication, adherence, compliance, nonadherence, noncompliance, cost

\section{Introduction}

In 2010 the costs of health care in the US exceeded \$2.7 trillion and accounted for $17.9 \%$ of the gross domestic product. Projections indicate health care will account for $20 \%$ of the US gross domestic product by $2020 .^{1-4}$ Twenty percent to $30 \%$ of dollars spent in the US health care system have been identified as wasteful. ${ }^{1,2,5}$ Providers and administrators have been challenged to contain costs by reducing waste and by improving the effectiveness of care delivered. Patient nonadherence to prescribed medications is associated with poor therapeutic outcomes, progression of disease, and an estimated burden of billions per year in avoidable direct health care costs. ${ }^{6-8}$ This review provides a general overview of nonadherence, its cost in specific illnesses, and approaches to improving medication adherence.

\section{Definition and measurement of medication adherence}

Patients are considered adherent to medications when they take prescribed agents at doses and times recommended by a health care provider and agreed to by the patient. ${ }^{9}$ As the health care community adopts the concepts of patient centeredness and activation, it is moving away from the term "compliance", which implies patient passivity in following the prescriber's recommendations. ${ }^{10}$ Medication persistence is the length of time from initiation to discontinuation of therapy. ${ }^{11,12}$

Adherence may be measured indirectly or directly as shown in Table 1 . Two indirect adherence metrics used in research and administrative work are the medication
Correspondence: Maura J McGuire Johns Hopkins Community Physicians, Johns Hopkins University School of Medicine, 3100 Wyman Park Drive, Baltimore, MD 2I2II, USA

Email mmcguirl@jhmi.edu 
possession ratio (MPR) and the proportion of days covered (PDC). MPR is calculated as the total number of days supplied, divided by the number of days between the first and last refills; while PDC is calculated as the total number of days supplied during an interval, divided by the total number of days during that interval. ${ }^{13}$ An MPR of $80 \%$ is often used as the cut off between adherence and nonadherence based on its ability to predict hospitalizations across selected high prevalence chronic diseases. ${ }^{14}$ These measures rely on pharmacy claims data, which does not account for the use of free drug samples, can miss coverage through a different insurance plans, and is insensitive to therapy changes. ${ }^{15,16}$ Insurance claims data also do not assess whether patients time doses, or use delivery devices, correctly. These protocols are important in conditions like COPD and asthma, where the way a patient uses inhaled therapy can also affect outcomes significantly. ${ }^{17}$

In clinical settings, adherence may be indirectly assessed using patient recall. Because patients may significantly overestimate adherence during self-reports, ${ }^{18}$ patient recall is more effectively interpreted when combined with a validated questionnaire to assess adherence barriers. ${ }^{19-21}$ Other methods such as pill counting and reviewing pill bottles against medication lists may provide important clinician

Table I Methods of measuring adherence

\begin{tabular}{|c|c|c|}
\hline Methods & $\begin{array}{l}\text { Data } \\
\text { source }\end{array}$ & Definition \\
\hline \multicolumn{3}{|c|}{ Indirect measurements used in research and administrative settings } \\
\hline MPR* & $\begin{array}{l}\text { Pharmacy } \\
\text { claims }\end{array}$ & $\begin{array}{l}=\text { (total days supplied)/(number of } \\
\text { days between the first and last refills) }\end{array}$ \\
\hline PDC* & $\begin{array}{l}\text { Pharmacy } \\
\text { claims }\end{array}$ & $\begin{array}{l}=\text { (total days supplied)/(number of } \\
\text { days in refill interval) }\end{array}$ \\
\hline \multicolumn{3}{|c|}{ Indirect measurements used in patient care settings } \\
\hline Self-report & Patient & $\begin{array}{l}\text { Patient recalls medications taken } \\
\text { in response to care team query }\end{array}$ \\
\hline Questionnaire & Provider & $\begin{array}{l}\text { Use of validated tool for adherence } \\
\text { markers }\end{array}$ \\
\hline Pill counting & Provider & $\begin{array}{l}\text { Staff member reviews patient supply } \\
\text { for doses remaining }\end{array}$ \\
\hline $\begin{array}{l}\text { Dose counting } \\
\text { device }\end{array}$ & Device & $\begin{array}{l}\text { Device includes electronic or manual } \\
\text { counter that tracks doses released }\end{array}$ \\
\hline $\begin{array}{l}\text { Electronic- } \\
\text { prescribing }\end{array}$ & $\begin{array}{l}\text { PBM } \\
\text { interface }\end{array}$ & $\begin{array}{l}\text { Reports transmitted from a } \\
\text { pharmacy benefit manager to } \\
\text { provider usually via EMR link }\end{array}$ \\
\hline \multicolumn{3}{|c|}{ Direct measurement } \\
\hline $\begin{array}{l}\text { Direct } \\
\text { observation }\end{array}$ & Provider & $\begin{array}{l}\text { Patient receives and takes medication } \\
\text { at health care facility }\end{array}$ \\
\hline $\begin{array}{l}\text { Drug levels } \\
\text { and markers }\end{array}$ & Laboratory & Patient blood or urine sample tested \\
\hline
\end{tabular}

Note: *Generally not used in direct patient care.

Abbreviations: MPR, medication possession ratio; PDC, proportion of days covered; PBM, pharmacy benefit manager; EMR, electronic medical records. insights and an opportunity for patient education. ${ }^{22}$ Bidirectional electronic (e)-prescribing interfaces which provide clinicians data on medication refill intervals at the time of care, are available in settings with electronic medical records. ${ }^{23}$ Electronic and mechanical dose counters provide estimates of adherence that can be reviewed during clinician visits; these may also improve adherence by providing patient reminders. ${ }^{24}$ Finally, clinicians may assume patients are adherent with medications when therapeutic goals are achieved. Like claims data, clinical setting measures lack the ability to verify doses are taken but require less time and expense to implement, compared to directly measured adherence.

Direct methods, including observed therapy, and blood or urine drug and metabolite concentrations are most commonly used in research when therapy involves high risk medications, or when public health needs merit the additional costs, invasiveness, and resources required to implement them..$^{9,25}$

\section{Optimizing expenditures and outcomes}

In 2010 spending for prescription drugs in the US was US\$259 billion. ${ }^{26}$ Considering the prevalent rates of nonadherence, drug-related expenses could increase substantially if adherence improved. Medication nonadherence is widespread and varied by disease, patient characteristics, and insurance coverage, with nonadherence rates ranging from $25 \%$ to $50 \%{ }^{6,27}$ In the US, nearly half of all adults have at least one chronic disease ${ }^{28}$ and the percentage of Americans taking at least one prescription drug increased from $38 \%$ in the period 1988-1994 to 49\% in the period 2007-2010; during the same time the number of adults taking three or more prescription drugs doubled. ${ }^{26}$ Prescription medication use will increase as the population ages. Based on these statistics, increasing adherence from current levels could increase medication expenses by billions of dollars.

Strategies to enhance adherence should consider the impact on overall health care costs, weighing increased drug expenditures against savings from improved outcomes. The majority of the costs attributed to medication nonadherence result from avoidable hospitalization. ${ }^{7}$ Additional direct costs are incurred by progression of controllable disease with: 1) increased service utilization at physician offices, emergency rooms, and urgent care and treatment facilities such as nursing homes, hospice, or dialysis centers; 2) avoidable pharmacy costs related to therapy intensification as comorbid conditions develop; and 3) diagnostic testing that could be avoided by controlling the primary illness. 
Because the adverse consequences of most chronic illnesses may not present for years, it is argued that additional expenditure to increase medication adherence might not be economically attractive to payers. Even in illnesses where total health care costs are lower in adherent patients, savings might reflect the impact of patient characteristics, other than adherence, that make them healthier overall than nonadherers. ${ }^{29}$ If this were true, investing resources in activating "unhealthy nonadherers" might not be cost effective. However, as discussed in our review, there is substantial evidence that the long term costs of poor outcomes exceed costs of medications in many chronic illnesses. ${ }^{7}$

In contrast, increasing adherence in mild illness may not save costs. If the cost of the medication is relatively high, while the baseline rate of hospitalizations and emergency department visits is low (eg, mild asthma or early human immunodeficiency infection), total health care costs may increase with better adherence. ${ }^{17,30}$ In cases like these, using low-cost generic medications and targeting higher severity patients may shift the balance towards cost savings.

Increasing adherence in patients with higher acuity may be a better investment, especially when rates of hospitalization are high. An estimated 10\% of hospitalizations in older adults may be caused by medication nonadherence. ${ }^{29,31}$ To prevent admissions and readmissions, payers and hospitals have implemented programs to improve medication adherence after discharge. ${ }^{32,33}$

\section{Medication adherence and health care costs}

The relationship between nonadherence and associated health care costs is shown in Figure 1. Medication nonadherence leads to poor outcomes, which then increase health care service utilization and overall health care costs. The financial pressure is passed to patients by payers through higher copayments, or via higher costs to employers for coverage. Increased patient cost sharing beyond a threshold negatively impacts the level of medication adherence. ${ }^{34}$ Figure 1 does not include other important drivers, such as the impact of reduced productivity, absenteeism, and increased disability on employers or society. It has been estimated that health-related productivity loss costs are 2.3 times higher than the direct health care costs. ${ }^{35}$ Therefore, the benefits of improved medication adherence may be even greater when considered at a societal level. However, most of the existing studies consider only direct health care costs when estimating the impact of nonadherence, and typically do not include productivity and

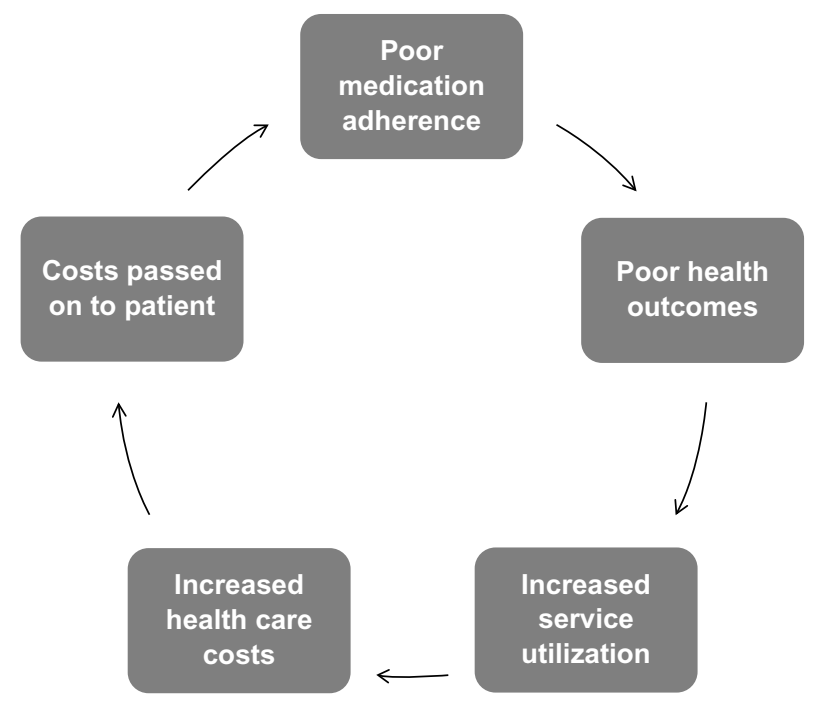

Figure I Conceptual diagram displaying a mechanism that may contribute to the maintenance of the medication nonadherence problem within the US health care system.

disability costs. ${ }^{17}$ Medication waste accounts for a small percentage of these costs. ${ }^{36,37}$

Between $\$ 100$ and $\$ 300$ billion of avoidable health care costs have been attributed to nonadherence in the US annually, representing $3 \%$ to $10 \%$ of total US health care costs. ${ }^{7,38}$ While there is substantial information relating nonadherence to poor patient outcomes, relatively few high quality studies report the impact on costs. The cost of nonadherence is generally determined by using administrative data to evaluate health care costs in populations of patients who are adherent compared to costs of populations of patients who are nonadherent. Systematic reviews of adherence note that differences in design, cost definitions, and included diagnosis (International Classification of Diseases [ICD]-9) groups, have varying levels of attributable-cost and make comparison of outcomes challenging. Over the last decade, the impact of adherence has been evaluated in association with numerous illnesses, including cardiovascular, pulmonary, gastrointestinal, metabolic, infectious, and psychiatric diseases. Representative findings are presented in our review, including summaries of systematic reviews when available.

\section{Cardiovascular disease}

Approximately $50 \%$ of patients with cardiovascular disease have poor adherence to their prescribed medications. ${ }^{39}$ In a 2009 review, Ho et al concluded "Surprisingly little is known about the association between medication adherence and health care costs in cardiovascular populations". ${ }^{12}$ In Medicare and Medicaid beneficiaries with congestive heart failure, Esposito et al found that total health care costs 
showed a graded relationship to adherence measured by MPR, and, were as much as 23\% less per year for adherent compared with nonadherent patients. ${ }^{40}$ A retrospective longitudinal analyses by Sun et al, of more than 1,300 patients with heart failure or myocardial infarction after acute hospitalization revealed that adherence and persistence with angiotensin receptor blockers and angiotensin converting enzyme inhibitors resulted in lower risk of rehospitalization and lower health care costs. ${ }^{41}$ Several studies have found strong associations between statin adherence and costs. In a retrospective cohort study of 381,422 patients using an integrated pharmacy and medical claims database, higher MPR was associated with reductions in subsequent total health care costs and cardiovascular disease-related hospitalizations. ${ }^{42}$ Another retrospective claims-based study of 1,705 patients with diabetes and hyperlipidemia showed that adherence decreased all-cause medical costs by $15 \% .{ }^{43}$ Sokol et al reported that in a retrospective cohort observation of 137,277 benefit plan patients, high levels of adherence were significantly associated with lower overall health care costs for diabetes, hypercholesterolemia, and hypertension, but not with congestive heart failure. ${ }^{29}$

\section{COPD}

In a 7-year retrospective administrative claims study of 55,076 chronic obstructive pulmonary disease (COPD) patients, Toy et al demonstrated an association between a high proportion of days covered (PDC) and fewer emergency department visits, and hospitalizations, resulting in a $2.2 \%$ reduction in overall costs. ${ }^{44} \mathrm{~A}$ similar study of 33,816 Medicare beneficiaries diagnosed with COPD by Simoni-Wastila et al found a reduction ( $\$ 2,185$ per patient) in the annual Medicare spending for patients with PDC higher than $80 \%$, compared to patients with PDC below $80 \% .{ }^{45}$ Stuart et al compared users and nonusers of maintenance medication for COPD, and found use of maintenance therapy was associated with significantly lower risks of hospitalization and rehospitalization and reduced Medicare expenditures. ${ }^{46}$

\section{Asthma}

In contrast to COPD, the studies have shown better adherence in asthma cohorts was associated with higher total health care costs. For example, a retrospective observational study of 18,456 Medicaid children aged 2-18 years diagnosed with asthma found lower rates of emergency room utilization, but did not demonstrate improved health care costs. ${ }^{17} \mathrm{~A}$ retrospective observational study using 2 years of claims data for 41,234 commercially insured asthmatics found overall costs increased with better adherence, except for patients in high-risk subgroups with past emergency department visits or hospital admission. ${ }^{30}$ Both studies suggest that improving medication adherence is cost saving in patients with severe disease, but increases overall costs in patients with mild disease, and a corresponding lower baseline rate of hospitalizations. ${ }^{17,30}$

\section{Depression}

In a retrospective study of patients initiating selective serotonin reuptake inhibitor (SSRI) therapy for depression and/or anxiety between July 2001 and June 2002, in a large national managed care database, Cantrell et al found approximately $43 \%$ of patients were adherent to antidepressant therapy, and adherent patients were associated with the lowest yearly medical costs. ${ }^{48}$ Conversely, a study of 65,753 managed care patients between 2001 and 2002, found medical charges (mainly related to inpatient treatment), excluding pharmacy charges, were lower for patients remaining on antidepressant drug therapy for at least 90 days, but that when drug costs were added there was no difference between adherent and nonadherent patients. ${ }^{49}$ Another study of 60,386 adult patients with depression studies showed adherent patients incurred an additional $\$ 806$ in overall health care expenditures compared to nonadherent patients, in the 6 months following initiation of antidepressant therapy. ${ }^{50}$

\section{Diabetes}

Multiple studies have evaluated the relationship of costs to diabetes, and generally support a correlation of increased adherence and reduced cost. One systematic review by Salas et al identified 209 studies, of which ten met inclusion criteria, and evidenced that despite significant methodological discrepancies among studies, low adherence was generally associated with higher costs. ${ }^{51}$ Another systematic review identified 449 relevant articles (12 met criteria) and reached similar conclusions. ${ }^{52}$ In a retrospective study of 57,687 patients, Hepke et al reported that overall health care costs were not lower among diabetic patients who were adherent with medications due to increased pharmaceutical costs, but suggested a threshold effect above which adherence was associated with reduced costs. ${ }^{16}$ Balkrishan et al found that each $10 \%$ increase in adherence was associated with an $8.6 \%$ to $28.9 \%$ decrease in total annual health care costs. ${ }^{47}$ More recently, in a longitudinal 4 year study of 740,195 veterans with type II diabetes, Egede found that nonadherent patients can have annual inpatient costs $41 \%$ higher compared to adherent patients, and concluded that significant 
costs could be avoided by increasing adherence. ${ }^{53}$ The level of cost savings varies with the type of diabetes medication considered. ${ }^{16,54}$

\section{HIVIAIDS}

In a retrospective cohort study of 325 previously antiretroviral medication-naïve human immunodeficiency virus (HIV)-infected individuals initiating first antiretroviral therapy from 1997 through 2003, Gardner et al showed that better adherence to antiretroviral medication was associated with decreased health care utilization and associated costs; however, because of the high cost of antiretroviral therapy, total medical costs were increased. ${ }^{55}$ A cohort study of 2,234 Medi-Cal patients with HIV reviewed outcomes in a patient subset served by medication therapy management (MTM) pharmacies versus other pharmacies; this documented higher medication adherence in MTM patients but no significant differences in total cost per patient per group. ${ }^{56}$ Among HIV-infected veterans, some with drug resistant HIV and multiple comorbid conditions, high adherence with antiretroviral therapy was associated with lower rates of inpatient hospitalization but no difference in total annual health care costs. ${ }^{57}$

\section{Other illnesses}

Studies of adherence and its impact on health care costs have been completed for other illnesses including musculoskeletal conditions, gastrointestinal and metabolic disorders, neurologic conditions, and others, and suggest varying levels of impact. ${ }^{6,9,30,58}$

\section{Determinants of patient adherence}

In order to improve medication adherence, clinicians must understand why patients fail to take prescribed medications. There is a large body of literature that investigates the determinants of medication nonadherence. These determinants can be categorized as patient related, provider related, and external factors. ${ }^{9,11}$ Patient related factors can be further divided into demographic, sociocultural and behavioral factors. ${ }^{59}$ External factors include disease characteristics, medication properties and system components. ${ }^{9,11}$ Figure 2 depicts the relationship of patient, provider and external factors.

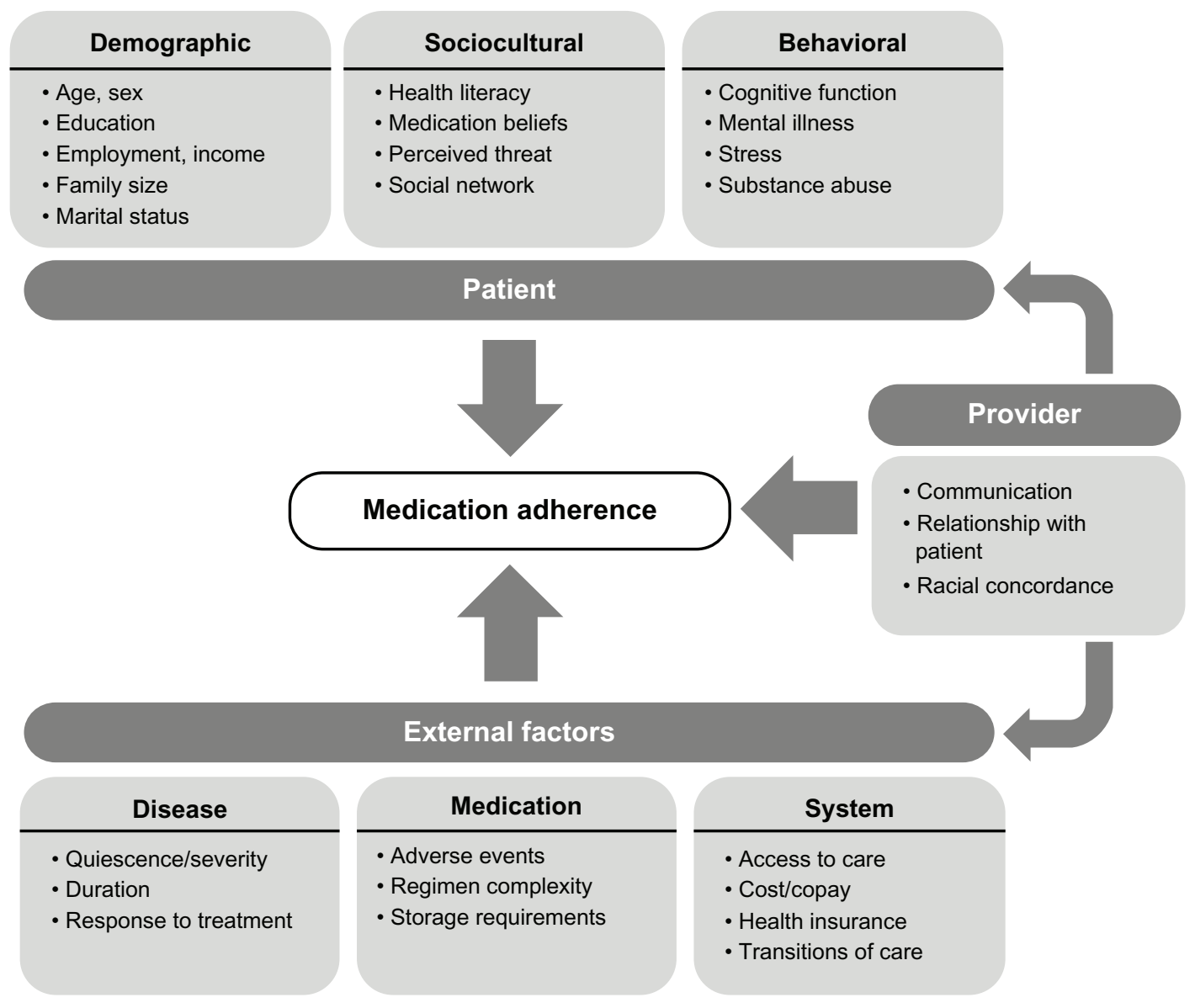

Figure 2 Selected determinants of medication adherence. 
Among patients, forgetting is the most frequently reported reason for nonadherence. ${ }^{60,61}$ In a survey of 10,000 patients, the most common reported reason for missing medications was forgetfulness $(24 \%)$, followed by perceived side effects (20\%), high drug costs $(17 \%)$, and perception that a prescribed medication would have little effect on their disease $(14 \%) .{ }^{62}$ In another survey of 14,464 Medicare beneficiaries, patients who did not fill at least one prescription reported the following reasons: "thought it would cost too much" (55.5\%), "medicine not covered by insurance" (20.2\%), "didn't think medicine was necessary for the condition" (18.0\%), and "was afraid of medicine reactions/contraindications" (11.8\%). ${ }^{63}$ More sophisticated patient assessment tools can elucidate psychological determinants such as self-reported medication self-efficacy, beliefs about medications and motivation that may impact adherence. ${ }^{19,64}$

In Figure 2, providers are positioned as connectors between patient and external factors. In an effective providerpatient relationship, providers will engage patients in shared decision making regarding medication needs and expected efficacy. Communication is central to the effectiveness of this relationship. Zolnierek et al estimated in a recent metaanalysis, that poor communication results in a $19 \%$ higher risk of nonadherence. ${ }^{65}$ Conversely, training physicians to improve their communication abilities leads to an improved chance of patient adherence. ${ }^{65}$ Factors like racial concordance can affect physician-patient communication and clinical decision making. A qualitative study conducted by Snipes et al concluded that black physicians were more inclined than white physicians to take into account a patient's race and cultural beliefs about disease when deciding among treatment alternatives. ${ }^{66}$ From a provider perspective, inadequate time and communication tools were perceived to be the most important barriers to enhancing adherence. ${ }^{67}$

Health care systems determine adherence in a number of ways. Restrictive formularies may limit access to prescribed medications and magnify patient barriers. ${ }^{68}$ Systems should ensure patient benefits support appropriate access and utilization, and develop provider payment models and patient management services that encourage adherence. The impact of out-of-pocket patient cost on adherence is discussed below.

Numerous interdependencies exist between patient, provider, and system. For example, a perceived threat from a specific disease may be influenced by a patient's sociocultural background, as well as the patient's personal experience with the disease and its severity. Patient perceptions may be further influenced by clinician-patient communication, the strength of which may be a function of the patient's cultural concordance and by system and provider factors. These relationships also suggest strategies that may enhance adherence.

\section{Strategies to increase patient adherence}

Strategies that may be used to increase medication adherence are presented in Table 2. These can be seen as targeting the patient, provider, and external determinants of adherence. A 2012 systematic review by Viswanathan et al evaluated interventions to improve adherence to self-administered medications for chronic disease, and found that reduced outof-pocket patient costs (ROPC), case management and patient education improved adherence in more than one condition. ${ }^{57}$ The review also found strong evidence for interventions such as collaborative care (in depression) and self-management (of asthma), but cautioned that benefits might not extend to other conditions. Disease self-management, patient engagement or "activation", as measured by the validated questionnaires, has been linked to better health outcomes. ${ }^{69,70}$

Reducing out-of-pocket costs leads to better medication adherence across many diagnoses. ${ }^{58}$ There is a linear relationship between the magnitude of patient cost sharing and the level of adherence. ${ }^{34}$

This relationship persists from low to higher income levels. A large survey found that a significant percentage (14\%) of high-income respondents also indicated cost-related nonadherence, despite relatively affordable copayments. ${ }^{71}$

Table 2 Selected strategies for improving medication adherence

\begin{tabular}{|c|c|}
\hline Strategies & Examples \\
\hline \multicolumn{2}{|l|}{ Patient } \\
\hline Education & $\begin{array}{l}\text { Patient counseling by physicians or other health } \\
\text { care personnel }^{58}\end{array}$ \\
\hline $\begin{array}{l}\text { Engage social } \\
\text { network }\end{array}$ & $\begin{array}{l}\text { Family members can provide reminders and } \\
\text { feedback. This is particularly helpful for patients } \\
\text { with psychiatric disease }^{85}\end{array}$ \\
\hline Reminders & Automated alerts, telemonitoring ${ }^{86}$ \\
\hline \multicolumn{2}{|l|}{ Provider } \\
\hline $\begin{array}{l}\text { Improve relationship } \\
\text { with patients }\end{array}$ & $\begin{array}{l}\text { Training physicians to improve their communication } \\
\text { skills, patient activation by improving patient- } \\
\text { physician communication }^{87}\end{array}$ \\
\hline \multicolumn{2}{|l|}{ External factors } \\
\hline Simpler regimen & Medications with long half-life or extended release 9 \\
\hline $\begin{array}{l}\text { Auto-delivery } \\
\text { systems }\end{array}$ & Eg, auto-injectors, pumps ${ }^{89}$ \\
\hline EMR based & Electronic prescribing ${ }^{81}$ \\
\hline $\begin{array}{l}\text { Team based care, } \\
\text { care coordination }\end{array}$ & $\begin{array}{l}\text { Patient centered medical homes; case management; } \\
\text { engagement of nursing staff, pharmacists }\end{array}$ \\
\hline $\begin{array}{l}\text { Value based } \\
\text { insurance designs }\end{array}$ & Lowering copayments can improve adherence ${ }^{34}$ \\
\hline
\end{tabular}

Abbreviation: EMR, electronic medical records. 
Whether ROPC will result in overall reductions in health care costs is less clear. Choudhry et al demonstrated that providing full prescription coverage to patients discharged after acute myocardial infarction improved mediation adherence by 4 to 6 percentage points but did not affect total health care costs despite some improvement in rates of subsequent first major vascular events. ${ }^{72}$ A 2013 consensus panel review called for additional work to assess the effectiveness of ROPC studies. ${ }^{73}$

Several studies have specifically reviewed use of financial incentives to increase medication adherence. A recent systematic review by DeFulio and Silverman identified 692 articles, 13 of which met inclusion criteria; across all studies, incentives increased adherence by a mean of 20 percentage points, but effects varied widely. ${ }^{74}$ Providing incentives that are at risk for nonadherence may be an effective strategy, based on the behavioral construct of "loss aversion" which states that people experience more dissatisfaction from the loss of a certain dollar amount than the satisfaction from the gain of the same amount. ${ }^{75}$ Two studies looking at the effect of lottery based incentives on anticoagulant adherence have had mixed results, but this concept needs further assessment. The impact on long term adherence has not yet been investigated. ${ }^{76,77}$

In contrast to population-based approaches, patientspecific approaches to nonadherence have been suggested. Marcum et al recently described use of validated adherence assessment tools to "diagnose" patient specific reasons for nonadherence, with subsequent effort directed at the specific barriers represented by that diagnosis..$^{20}$ This strategy suggests benefit for incorporating standard screening tools into patient interviews and reflects a need for patient centeredness in care delivery.

\section{The way forward}

Additional work is needed to elucidate the cost and impact of effort to improve adherence of patients. Because many reports studying the impact of medication adherence on health care costs are based on retrospective observational studies; it is difficult to prove causality between changes in medication adherence and corresponding effects on health care costs. Studies may be affected by the "healthy adherer" phenomenon, which occurs because healthier people may be more adherent, but also have better outcomes independent of the drug's therapeutic impact. ${ }^{54}$ As a consequence, it has been argued that more clinical trials, where randomization could remove some sources of bias, should be designed to directly investigate the cost impact. ${ }^{29}$ Because of the insensitivity of current diagnosis groups to disease severity or stage, as in congestive heart failure or asthma, the planned national implementation of ICD-10, which has much more specificity, may improve identification of specific populations where efforts to increase adherence would achieve greatest gains.

Team-based case management is already recognized as an effective care strategy that improves adherence and health outcomes, and can decrease overall medical care costs. The guiding principles of patient-centered medical homes include the maintenance of a longitudinal patient relationship with a personal physician together with a multidisciplinary care team who together take a whole-person approach and coordinate care across settings is also a key component. ${ }^{78}$ Since the "medical home" model is relatively new and still under assessment, its impact on health care costs as related to improvements in medication adherence remains to be fully demonstrated.

Pharmacists can play integral roles within medical homes. ${ }^{79}$ Pharmacist led multi-pronged interventions have indeed been demonstrated to improve outcomes. ${ }^{58}$ From a legislative perspective, the Medicare Modernization Act of 2003 required Medicare part D plans to implement medication therapy management services provided by clinical pharmacists, while the 2010 Affordable Care Act provided more guidance and expanded patient eligibility. ${ }^{80}$ These services include a comprehensive assessment of current medications, which includes counseling regarding the importance of adherence, and the design of a medication related action plan. ${ }^{81} \mathrm{~A}$ recent review of studies evaluating medication therapy management programs has identified key elements that improve outcomes, such as providing services to patients with specific therapeutic problems, having routine communications with primary care providers, and having regular follow-up to encourage medications adherence after changes in the medication regimen. ${ }^{82}$

E-prescribing is another intervention with the potential to improve medication adherence and total health care costs, and is becoming more widely used as electronic medical records are integrated into medical practices. E-prescribing differs from simple transmission of prescriptions directly to pharmacies and allows prescribers to receive an electronic notice from the pharmacy telling them that a patient's prescription has been picked up, not picked up, or has been partially filled, to help monitor medication adherence in patients with chronic conditions. A recent study, conducted by Surescripts in collaboration with pharmacies and pharmacy benefit managers, analyzed over 40 million prescription records, observing that e-prescribing increased the percentage of 
new prescriptions that were picked up by patients from the pharmacy by $10 \%$, compared to paper prescriptions. In the absence of e-prescribing, only $73.2 \%$ of paper prescriptions make it to the pharmacy and an even smaller percentage of the total prescriptions written are picked up by patients. The same study estimated that e-prescribing and the corresponding increase in first-fill medication adherence would save at least $\$ 140$ billion over the following decade. ${ }^{83}$ Additional studies to validate the impact of e-prescribing systems and electronic medical records on adherence and related cost savings are needed. ${ }^{84}$

\section{Conclusion}

Medication nonadherence is a significant contributor to avoidable health care costs in this country. While impact on disease outcome and cost is more pronounced in some illnesses than others, stakeholders agree that increasing medication adherence would improve health outcomes and save billions of dollars. Improved adherence can be achieved through better education, value-based insurance designs, and thoughtful use of patient incentives. Ultimately collaboration between patients, payers, policy makers and providers, and redesigning systems to employ more team-based care, use lower cost medications, and target highest cost illnesses, will be needed to achieve better adherence and optimize spending.

\section{Disclosure}

The authors report no conflicts of interest in this work.

\section{References}

1. Centers for Medicare and Medicaid Services, editor. NHE Projections 2010-2020. Washington, DC: US Department of Health and Human Services; 2011.

2. Kaiser Family Foundation, editor. Health care costs: a primer. Available from: http:www.kff.org/insurance/upload/7670-7603.pdf. Accessed August 7, 2013.

3. Schroeder SA. Shattuck lecture. We can do better-improving the health of the American people. N Engl J Med. 2007;357(12):1221-1228.

4. The US Department of Treasury, ed. The 2012 annual report of the boards of trustees of the federal hospital insurance and federal supplementary medical insurance trust funds; 2012. Available from: http://www. treasury.gov/resource-center/economic-policy/ss-medicare/Documents/ TR_2012_Medicare.pdf. Accessed August 7, 2013.

5. Berwick DM, Hackbarth AD. Eliminating waste in US health care. JAMA. 2012;307(14):1513-1516.

6. DiMatteo MR. Variations in patients' adherence to medical recommendations: a quantitative review of 50 years of research. Med Care. 2004;42(3):200-209.

7. IMS Institute for Healthcare Informatics. Avoidable costs in US health care. 2013. Available at: http://www.imshealth.com/ deployedfiles/imshealth/Global/Content/Corporate/IMS\%20Institute/ RUOM-2013/IHII_Responsible_Use_Medicines_2013.pdf. Accessed September 10, 2013.

8. DiMatteo MR. Evidence-based strategies to foster adherence and improve patient outcomes. JAAPA. 2004;17(11):18-21.
9. Osterberg L, Blaschke T. Adherence to medication. $N$ Engl J Med. 2005;353(5):487-497.

10. Hansen RA, Farley JF, Droege M, Maciejewski ML. A retrospective cohort study of economic outcomes and adherence to monotherapy with metformin, pioglitazone, or a sulfonylurea among patients with type 2 diabetes mellitus in the United States from 2003 to 2005. Clin Ther. 2010;32(7):1308-1319.

11. Bosworth HB, Granger BB, Mendys P, et al. Medication adherence: A call for action. Am Heart J. 2011;162(3):412-424.

12. Ho PM, Bryson CL, Rumsfeld JS. Medication adherence: Its importance in cardiovascular outcomes. Circulation. 2009;119(23): 3028-3035.

13. LaFleur J, Oderda GM. Methods to measure patient compliance with medication regimens. J Pain Palliat Care Pharmacother. 2004;18(3): $81-87$.

14. Karve S, Cleves MA, Helm M, Hudson TJ, West DS, Martin BC. Good and poor adherence: Optimal cut-point for adherence measures using administrative claims data. Curr Med Res Opin. 2009;25(9): 2303-2310.

15. Sikka R, Xia F, Aubert RE. Estimating medication persistency using administrative claims data. Am J Manag Care. 2005;11(7):449-457.

16. Hepke KL, Martus MT, Share DA. Costs and utilization associated with pharmaceutical adherence in a diabetic population. Am J Manag Care. 2004;10(2 Pt 2):144-151.

17. Herndon JB, Mattke S, Evans Cuellar A, Hong SY, Shenkman EA. Anti-inflammatory medication adherence, health care utilization and expenditures among medicaid and children's health insurance program enrollees with asthma. Pharmacoeconomics. 2012;30(5):397-412.

18. Express Scripts. 2011 drug trend report. 2012. Available from: http://www.drugtrendreport.com/docs/DTR-2011.pdf. Accessed September 21, 2013.

19. Lavsa SM, Holzworth A, Ansani NT. Selection of a validated scale for measuring medication adherence. J Am Pharm Assoc (2003). 2011; 51(1):90-94.

20. Marcum ZA, Sevick MA, Handler SM. Medication nonadherence: A diagnosable and treatable medical condition. JAMA. 2013;309(20): 2105-2106.

21. Morisky DE, Green LW, Levine DM. Concurrent and predictive validity of a self-reported measure of medication adherence. Med Care. 1986;24(1):67-74.

22. Martinez ML, Vande Griend JP, Linnebur SA. Medication management: A case of brown bag-identified medication hoarding. Consult Pharm. 2012;27(10): 729-736.

23. Harbig P, Barat I, Lund Nielsen P, Damsgaard EM. Instantaneous detection of nonadherence: Quality, strength, and weakness of an electronic prescription database. Pharmacoepidemiol Drug Saf. 2012;21(3): 323-328.

24. Rand CS, Wise RA. Measuring adherence to asthma medication regimens. Am J Respir Crit Care Med. 1994;149(2 Pt 2):S69-S76; discussion S77-S78.

25. Lauzardo M, Peloquin CA. Antituberculosis therapy for 2012 and beyond. Expert Opin Pharmacother. 2012;13(4):511-526.

26. National Center for Health Statistics. Health, United States, 2012: With special feature on emergency care. 2013. Available from: http://www. cdc.gov/nchs/data/hus/hus12.pdf. Accessed September 21, 2013.

27. Haynes RB, Montague P, Oliver T, McKibbon KA, Brouwers MC, Kanani R. Interventions for helping patients to follow prescriptions for medications. Cochrane Database Syst Rev. 2000;(2): CD000011.

28. Centers for Disease Control and Prevention. Chronic diseases and health promotion; 2013. Available from: http://www.cdc.gov/chronicdisease/ overview/index.htm. Accessed September 21, 2013.

29. Sokol MC, McGuigan KA, Verbrugge RR, Epstein RS. Impact of medication adherence on hospitalization risk and health care cost. Med Care. 2005;43(6):521-530.

30. Mattke S, Martorell F, Hong SY, Sharma P, Cuellar A, Lurie N. Anti-inflammatory medication adherence and cost and utilization of asthma care in a commercially insured population. J Asthma. 2010;47(3):323-329. 
31. Vermiere E, Avonts D, Van Royen P, Buntinx F, Denekens J. Context and health outcomes. Lancet. 2001;357(9273):2059-2060.

32. Sarangarm P, London MS, Snowden SS, et al. Impact of pharmacist discharge medication therapy counseling and disease state education: Pharmacist assisting at routine medical discharge (project PhARMD). Am J Med Qual. 2013;28(4):292-300.

33. Hesselink G, Schoonhoven L, Barach P, et al. Improving patient handovers from hospital to primary care: A systematic review. Ann Intern Med. 2012;157(6):417-428.

34. Eaddy MT, Cook CL, O'Day K, Burch SP, Cantrell CR. How patient cost-sharing trends affect adherence and outcomes: A literature review. P T. 2012;37(1):45-55.

35. Loeppke R, Taitel M, Haufle V, Parry T, Kessler RC, Jinnett K. Health and productivity as a business strategy: A multiemployer study. J Occup Environ Med. 2009;51(4):411-428.

36. Morgan TM. The economic impact of wasted prescription medication in an outpatient population of older adults. J Fam Pract. 2001;50(9): 779-781.

37. Bain T. Public health implications of household pharmaceutical waste in the United States. Health Services Insights. 2010;(3):21.

38. Benjamin RM. Medication adherence: Helping patients take their medicines as directed. Public Health Rep. 2012;127(1):2-3.

39. Kronish IM, Ye S. Adherence to cardiovascular medications: Lessons learned and future directions. Prog Cardiovasc Dis. 2013;55(6): $590-600$.

40. Esposito D, Bagchi AD, Verdier JM, Bencio DS, Kim MS. Medicaid beneficiaries with congestive heart failure: Association of medication adherence with health care use and costs. Am J Manag Care. 2009;15(7): 437-445.

41. Sun SX, Ye X, Lee KY, Dupclay L Jr, Plauschinat C. Retrospective claims database analysis to determine relationship between reninangiotensin system agents, rehospitalization, and health care costs in patients with heart failure or myocardial infarction. Clin Ther. 2008; 30 Pt 2:2217-2227.

42. Pittman DG, Chen W, Bowlin SJ, Foody JM. Adherence to statins, subsequent health care costs, and cardiovascular hospitalizations. $\mathrm{Am}$ J Cardiol. 2011;107(11):1662-1666.

43. Wu J, Seiber E, Lacombe VA, Nahata MC, Balkrishnan R. Medical utilization and costs associated with statin adherence in medicaid enrollees with type 2 diabetes. Ann Pharmacother. 2011;45(3): 342-349.

44. Toy EL, Beaulieu NU, McHale JM, et al. Treatment of COPD: Relationships between daily dosing frequency, adherence, resource use, and costs. Respir Med. 2011;105(3):435-441.

45. Simoni-Wastila L, Wei YJ, Qian J, et al. Association of chronic obstructive pulmonary disease maintenance medication adherence with all-cause hospitalization and spending in a medicare population. Am J Geriatr Pharmacother. 2012;10(3):201-210.

46. Stuart BC, Simoni-Wastila L, Zuckerman IH, et al. Impact of maintenance therapy on hospitalization and expenditures for medicare beneficiaries with chronic obstructive pulmonary disease. Am J Geriatr Pharmacother. 2010;8(5):441-453.

47. Balkrishnan R, Rajagopalan R, Camacho FT, et al. Predictors of medication adherence and associated health care costs in an older population with type 2 diabetes mellitus: a longitudinal cohort study. Clin Ther. 2003 Nov;25(11):2958-2971.

48. Cantrell CR, Eaddy MT, Shah MB, Regan TS, Sokol MC. Methods for evaluating patient adherence to antidepressant therapy: A realworld comparison of adherence and economic outcomes. Med Care. 2006;44(4):300-303

49. Eaddy MT, Druss BG, Sarnes MW, Regan TS, Frankum LE. Relationship of total health care charges to selective serotonin reuptake inhibitor utilization patterns including the length of antidepressant therapy - results from a managed care administrative claims database. J Manag Care Pharm. 2005;11(2):145-150.

50. Robinson RL, Long SR, Chang S, et al. Higher costs and therapeutic factors associated with adherence to NCQA HEDIS antidepressant medication management measures: Analysis of administrative claims. J Manag Care Pharm. 2006;12(1):43-54.
51. Salas M, Hughes D, Zuluaga A, Vardeva K, Lebmeier M. Costs of medication nonadherence in patients with diabetes mellitus: A systematic review and critical analysis of the literature. Value Health. 2009;12(6): 915-922.

52. Breitscheidel L, Stamenitis S, Dippel FW, Schoffski O. Economic impact of compliance to treatment with antidiabetes medication in type 2 diabetes mellitus: A review paper. $J$ Med Econ. 2010;13(1):8-15.

53. Egede LE, Gebregziabher M, Dismuke CE, et al. Medication nonadherence in diabetes: Longitudinal effects on costs and potential cost savings from improvement. Diabetes Care. 2012;35(12):2533-2539.

54. Stuart B, Davidoff A, Lopert R, Shaffer T, Samantha Shoemaker J, Lloyd J. Does medication adherence lower medicare spending among beneficiaries with diabetes? Health Serv Res. 2011;46(4):1180-1199.

55. Gardner EM, Maravi ME, Rietmeijer C, Davidson AJ, Burman WJ. The association of adherence to antiretroviral therapy with health care utilization and costs for medical care. Appl Health Econ Health Policy. 2008;6(2-3):145-155.

56. Hirsch JD, Gonzales M, Rosenquist A, Miller TA, Gilmer TP, Best BM. Antiretroviral therapy adherence, medication use, and health care costs during 3 years of a community pharmacy medication therapy management program for medi-cal beneficiaries with HIV/AIDS. J Manag Care Pharm. 2011;17(3):213-223.

57. Barnett PG, Chow A, Joyce VR, et al. Determinants of the cost of health services used by veterans with HIV. Med Care. 2011;49(9):848-856.

58. Viswanathan $\mathrm{M}$, Golin $\mathrm{CE}$, Jones $\mathrm{CD}$, et al. Interventions to improve adherence to self-administered medications for chronic diseases in the United States: A systematic review. Ann Intern Med. 2012.

59. Krueger KP, Berger BA, Felkey B. Medication adherence and persistence: A comprehensive review. Adv Ther. 2005;22(4):313-356.

60. Boskovic J, Leppee M, Culig J, Eric M. Patient self-reported adherence for the most common chronic medication therapy. Scand J Public Health. 2013;41(4):333-335.

61. Barfod TS, Sorensen HT, Nielsen H, Rodkjaer L, Obel N. 'Simply forgot' is the most frequently stated reason for missed doses of HAART irrespective of degree of adherence. HIV Med. 2006;7(5):285-290.

62. Boston Consulting Group. The hidden epidemic: finding a cure for unfilled prescriptions and missed doses. 2003. Available from: http://www.bcg.com/documents/file14265.pdf. Accessed September 10, 2013.

63. Kennedy J, Tuleu I, Mackay K. Unfilled prescriptions of medicare beneficiaries: Prevalence, reasons, and types of medicines prescribed. J Manag Care Pharm. 2008;14(6):553-560.

64. Voils CI, Maciejewski ML, Hoyle RH, et al. Initial validation of a self-report measure of the extent of and reasons for medication nonadherence. Med Care. 2012;50(12):1013-1019.

65. Zolnierek KB, Dimatteo MR. Physician communication and patient adherence to treatment: A meta-analysis. Med Care. 2009;47(8): 826-834.

66. Snipes SA, Sellers SL, Tafawa AO, Cooper LA, Fields JC, Bonham VL. Is race medically relevant? A qualitative study of physicians' attitudes about the role of race in treatment decision-making. BMC Health Serv Res. 2011;11:183-6963.

67. Brunton SA. Improving medication adherence in chronic disease management. J Fam Pract. 2011;60(4):S1-S8.

68. Braithwaite S, Shirkhorshidian I, Jones K, Johnsrud M. The role of medication adherence in the US healthcare system. 2013. Available from: http://static.correofarmaceutico.com/docs/2013/06/24/adher.pdf. Accessed September 10, 2013.

69. Greene J, Hibbard JH. Why does patient activation matter? an examination of the relationships between patient activation and healthrelated outcomes. J Gen Intern Med. 2012;27(5):520-526.

70. Hibbard JH, Stockard J, Mahoney ER, Tusler M. Development of the patient activation measure (PAM): Conceptualizing and measuring activation in patients and consumers. Health Serv Res. 2004;39(4 Pt 1):1005-1026.

71. Piette JD, Beard A, Rosland AM, McHorney CA. Beliefs that influence cost-related medication non-adherence among the "haves" and "have nots" with chronic diseases. Patient Prefer Adherence. 2011;5:389-396. 
72. Choudhry NK, Avorn J, Glynn RJ, et al. Full coverage for preventive medications after myocardial infarction. $N$ Engl J Med. 2011;365(22): 2088-2097.

73. Community Preventive Services Task Force. Annual report to congress. 2013. Available from: http://www.thecommunityguide.org/ annualreport/2013-congress-report-full.pdf. Accessed September 21, 2013.

74. DeFulio A, Silverman K. The use of incentives to reinforce medication adherence. Prev Med. 2012;55 Suppl:S86-S94.

75. Kimmel SE, Troxel AB. Novel incentive-based approaches to adherence. Clin Trials. 2012;9(6):689-695.

76. Volpp KG, Loewenstein $\mathrm{G}$, Troxel AB, et al. A test of financial incentives to improve warfarin adherence. BMC Health Serv Res. 2008;8:272.

77. Kimmel SE, Troxel AB, Loewenstein G, et al. Randomized trial of lottery-based incentives to improve warfarin adherence. Am Heart J. 2012;164(2):268-274.

78. Rosenthal TC. The medical home: Growing evidence to support a new approach to primary care. J Am Board Fam Med. 2008;21(5):427-440.

79. Smith M, Bates DW, Bodenheimer T, Cleary PD. Why pharmacists belong in the medical home. Health Aff (Millwood). 2010;29(5): 906-913.

80. Lee-Wilson C. MA. Establishing a medication therapy management (MTM) practice: Obtaining compensation for clinical services. Maryland Pharmacist. 2011:3.

81. National Conference of State Legislatures. Medication therapy management: Pharmaceutical safety and savings. National Conference of State Legislatures Web site. http://www.ncsl.org/issues-research/health/ medication-therapy-management.aspx. Accessed December 19, 2012.
82. Kucukarslan SN, Hagan AM, Shimp LA, Gaither CA, Lewis NJ. Integrating medication therapy management in the primary care medical home: A review of randomized controlled trials. Am J Health Syst Pharm. 2011;68(4):335-345.

83. E-prescribing shown to improve outcomes, save billions. Study quantifies relationship between e-prescribing and medication adherence, with potential savings of $\$ 140$ billion over the next 10 years. Health Manag Technol. 2012;33(4):22-23.

84. Blumenthal D, Tavenner M. The "meaningful use" regulation for electronic health records. N Engl J Med. 2010;363(6):501-504.

85. McDonald HP, Garg AX, Haynes RB. Interventions to enhance patient adherence to medication prescriptions: Scientific review. JAMA. 2002;288(22):2868-2879.

86. Granger BB, Bosworth HB. Medication adherence: Emerging use of technology. Curr Opin Cardiol. 2011;26(4):279-287.

87. Cooper LA, Roter DL, Carson KA, et al. A randomized trial to improve patient-centered care and hypertension control in underserved primary care patients. J Gen Intern Med. 2011;26(11):1297-1304.

88. Kripalani S, Yao X, Haynes RB. Interventions to enhance medication adherence in chronic medical conditions: A systematic review. Arch Intern Med. 2007;167(6):540-550.

89. Golay A. Pharmacoeconomic aspects of poor adherence: can better adherence reduce healthcare costs? J Med Econ. 2011;14(5):594-608.
Risk Management and Healthcare Policy

\section{Publish your work in this journal}

Risk Management and Healthcare Policy is an international, peerreviewed, open access journal focusing on all aspects of public health, policy, and preventative measures to promote good health and improve morbidity and mortality in the population. The journal welcomes submitted papers covering original research, basic science, clinical \& epidemio-

\section{Dovepress}

logical studies, reviews and evaluations, guidelines, expert opinion and commentary, case reports and extended reports. The manuscript management system is completely online and includes a very quick and fair peerreview system, which is all easy to use. Visit http://www.dovepress.com/ testimonials.php to read real quotes from published authors. 